\title{
Novel implementation of experiential learning in health and wellbeing in a university setting
}

\author{
Maria Heffernan ${ }^{1,2}$, Patricia Fitzpatrick ${ }^{1,2}$, Amy Bermingham ${ }^{1}$, Ross Neville ${ }^{1}$, Nicola \\ Dervan $^{1,3}$, Clare Corish ${ }^{1,3}$, Celine Murrin ${ }^{1,2}$, Brian Mullins ${ }^{2}$ \\ ${ }^{1}$ School of Public Health, Physiotherapy and Sports Science, University College Dublin, \\ Ireland, ${ }^{2}$ Healthy UCD, University College Dublin, Ireland, ${ }^{3}$ Institute of Food and Health, \\ University College Dublin, Ireland.
}

\begin{abstract}
Healthy UCD is a health promotion initiative in University College Dublin (UCD) which aims to create a sustainable healthy campus for all members of the UCD community. In recent years, Healthy UCD has worked with staff from across the university to provide opportunities for experiential learning to UCD students in areas related to health and wellbeing. The initiative currently has involvement in three modules: 1) Practice Placement-a core MSc in Clinical Nutrition and Dietetics module where students plan and implement a university-wide Healthy Eating Week, 2) Event Management - a core module undertaken by second-year BSc Sport \& Exercise Management students, and 3) Student Health \& Wellbeing - an undergraduate elective module which challenges students to reflect on issues which affect their own health and wellbeing and that of those around them and then develop a student-focused Healthy UCD campaign. This paper will outline how experiential learning is implemented in these modules, how students are assessed, and the perceptions of students who complete these modules.
\end{abstract}

Keywords: Experiential learning; wellbeing; health promotion; university; education. 


\section{Introduction}

University College Dublin (UCD) is the largest university in Ireland, located in the capital city, Dublin, with over 33,000 students and 3,700 staff (full-time equivalents) ("University College Dublin - UCD by Numbers," 2021). Healthy UCD is a health promotion initiative designed to create a sustainable healthy campus in UCD for all members of the University community ("Healthy UCD," 2021). Healthy UCD has an active steering committee with representation from across the university, a director of Health Promotion, and a budget that covers salary for one research assistant/health promotion officer. The initiative has fostered a close liaison with staff from key areas across the university, and with the Students Union and the Student Societies. Since its establishment in 2016, Healthy UCD has worked to make opportunities for healthy living available to all members of the UCD community through initiatives to promote healthy eating, physical activity and mental wellbeing. In more recent years, the Healthy UCD team has worked to provide experiential learning opportunities to UCD students in these areas.

Experiential learning, as defined by Kolb (1984), describes learning as a continuous process where individuals are actively involved in new experiences, reflect on these experiences and theorise about them, before applying this knowledge to new situations. This style of learning therefore lends itself well to a university setting as students can learn through the planning and implementation of a project or initiative, evaluate how successful it was, and apply their new knowledge to further university experiences or in their future career.

Helping students to become career-ready is commonly cited as a motivation for introducing experiential learning in a university setting in previous descriptions of its application. Some studies also place emphasis on the benefits students perceive they obtain from this type of learning. One such study conducted in Singapore introduced experiential learning-based modules aimed at preparing students for a work environment and compared these to traditional modules within the same university (Seow, Pan et al., 2019). It was found that students who completed the experiential learning-based modules had a greater improvement in problem-solving skills compared to those who did not (although the difference was not significant) and that feedback from students suggested they perceived the experiential learning approach enhanced their learning experience. Another study examining experiential learning in a retailing laboratory reported that the approach developed skills valued by employers such as critical thinking, analytical and decision-making skills whilst also maintaining student motivation and satisfaction (Franco Valdez \& Valdez Cervantes, 2018).

Healthy UCD is currently involved in three modules available to students in UCD. It coordinates and delivers one elective undergraduate module entitled "Student Health and Wellbeing" and contributes to two core modules taken by postgraduate students undertaking an MSc in Clinical Nutrition and Dietetics and undergraduate students undertaking a BSc in 
Sport \& Exercise Management. Experiential learning forms a large component of these modules and is a significant contributor to assessment in each one. This paper aims to outline how experiential learning is implemented in these modules and the benefits to both students and the wider university.

\section{Modules where Healthy UCD provides experiential learning opportunities}

\subsection{Practice Placement (non-acute)}

The MSc in Clinical Nutrition and Dietetics is a postgraduate programme that develops competent practitioners who, upon successful completion, are eligible to apply for state registration as a Dietitian. In a core practice placement module ("Practice Placement (nonacute) (PHPS40910)," 2021), the students work with Healthy UCD to prepare and deliver a campus-wide week-long event 'Healthy Eating Week' which is held each academic year ("Healthy UCD | Healthy Eating Week 2019," 2021; "Healthy UCD | Healthy Eating Week February 2020," 2021; "Healthy UCD | Healthy Eating Week November 2020," 2021). The students decide on the content of the information to be disseminated and are tasked with designing the event to maximise reach and engagement by staff and students across the campus. They are assessed under the following competencies, which are mapped to the standards of proficiency required to register as a Dietitian in Ireland: i) the planning, delivery and evaluation of a health promoting project, ii) the planning and delivery of group education, iii) the production of appropriate written communications and reports, iv) effective communication and collaboration with colleagues, including modification of communication when appropriate, v) the building and management of professional relationships, vi) presenting to a professional audience, and vii) understanding the role of a dietitian within the public health setting.

Healthy Eating Week originated in 2017 as an event organised by Healthy UCD staff with input from student volunteers and societies. In 2019, a decision was made to convert Healthy Eating Week into an experiential learning component of the Practice Placement (non-acute) module for MSc in Clinical Nutrition and Dietetics students. Since then, two student-led editions of Healthy Eating Week have taken place, differing in their mode of delivery due to the circumstances in which they took place. The first of these took place in the 2019/2020 academic year in a traditional in-person format, with the theme of "mythbusting" chosen for the week. A variety of events were organised and delivered by students on the UCD campus including a talk given by a sports nutritionist, a panel discussion on food sustainability, tastetesting of branded and unbranded foods, and posters designed to look like a social media feed dispelling common food myths displayed around the campus.

The students organising Healthy Eating Week in the 2020/2021 academic year faced an additional challenge during their learning experience: due to Covid-19 public health 
restrictions and campus closure, with all university business moved online (except for essential on-campus activity), it was necessary for them to deliver a virtual event. To achieve this, the students utilised the Healthy UCD website and social media channels to host content in creative formats. Rather than choosing an overall theme for the week, the 2020/2021 students selected an individual theme for each day of the four-day event, namely 'All things breakfast', 'Eat well for less', 'Keep it movin' (nutrition and exercise) and 'Snack attack' (healthy snacking). Content was delivered through infographics, videos, articles and podcasts. The virtual nature of this event required the students to develop a suitable evaluation plan to capture engagement with the virtual event and utilised website and social media analytics along with a questionnaire aimed at those who engaged with Healthy Eating Week content.

Feedback from these students has included an improvement of their understanding of a health promotion role, greater understanding of good leadership and the importance of assigning specific tasks to team members. All students achieved health promotion nutrition competencies as well as competency in communication, team-working and professionalism from designing, implementing and evaluating this initiative. The competencies are mapped to the proficiencies required by the state regulator of Dietitians in Ireland and were assessed by registered dietitians.

Students involved in the 2020/2021 edition of Healthy Eating Week prepared an evaluation report of their event, highlighting key outcomes. This included Healthy Eating Week material being seen by 3,085 Instagram accounts across the event and growing Healthy UCD's following by $14.4 \%$, along with views from an average of 2,267 accounts on Twitter on each day of the event. Over 150 people took part in competitions across the event including a healthy baking competition and end-of-week quiz. Students also completed a feedback form giving their own views on the event. The majority felt that the event was a success $(95 \%)$, and that they were sufficiently supported by Healthy UCD and their tutors throughout (65\%). However, $60 \%$ of the group felt that they needed more time allocated to Healthy Eating Week preparation in their programme of study. Also in 2021, Healthy UCD piloted engagement with marketing students from the UCD School of Business who reviewed the social media activity from Healthy Eating week as part of their coursework and have provided recommendations for how to improve in the future.

\subsection{Event Management module - theory and practice}

This 2-trimester undergraduate core module introduces the process of preparing for an event to $2^{\text {nd }}$ year BSc Sport \& Exercise Management students, taking into consideration a wide range of practical and logistical issues ("Event Management, Autumn Trimester (SMGT20010)," 2021; "Event Management, Spring Trimester (SMGT20210)," 2021). The project involves the group working in teams to develop a comprehensive bid document in 
Trimester 1 to promote and deliver a Healthy UCD event as an assessed part of their module. In Trimester 2, a winning bid is selected, with inclusion of the best suggestions from the other bids. The students are responsible for planning, delivering and evaluating this wellbeing event with Healthy UCD as their "real life" client. The students are assigned roles on teams responsible for operations, activities and communications and are awarded academic credits based on their performance.

Similar to Healthy Eating Week, students in this module must create engaging content and use novel methods of engaging with the UCD community. Previously, students have organised live, in-person activities under the banner of "Wellbeing Wednesday" held in the student centre in UCD, such as lunchtime yoga classes and competitions in bowling and rowing, with prize sponsorship sought by the students themselves. An online edition of the 2021 event was held which, similar to Healthy Eating Week, was rolled out using the Healthy UCD website and social media channels under the theme of "Wellbeing Your Way". This included live online seminars on healthy eating and mental wellbeing, along with fitness classes and a competition which invited members of the UCD community to submit photos capturing what wellbeing means to them. Each seminar and fitness class received an average of 460 views across all platforms during the event, while 104 members of the UCD community took part in an online quiz held at the end of the event. The students completed an evaluation after their event and reported achieving their goal of increasing Healthy UCD's Instagram following by $5 \%$. However, this target was not reached for Twitter; students advised they had learned the importance of tailoring content for different social media platforms in order to improve engagement. Other key learnings reported included an understanding of the responsibilities of running a professional event and how to deliver such an event while operating both in small groups and as a larger team.

\subsection{Student Health and Wellbeing - an undergraduate elective module}

The Health Promotion Strategy for the University led to the development of Healthy UCD, but also introduced the idea of module development in this subject area ("Healthy UCD | Healthy UCD Strategy," 2016). The module Student Health \& Wellbeing was introduced as an undergraduate elective module, with $50 \%$ of places held specifically for first year students, which enables students to reflect on some of the issues that affect their own health and wellbeing and that of their family and friends ("Student Health \& Wellbeing (PHPS10010)," 2021). Students are encouraged to look at what drives lifestyle-related behaviours and the broader socio-ecological influences that often shape our decisions. Participants in this module research and design a campus health promotion initiative as their final assessment; a non-marked pitch presentation allows the students to discuss their ideas with the module coordinator and other Healthy UCD staff, with a final presentation subsequently assessed. Examples of such initiatives presented by students include outdoor mindfulness areas, an anonymous online mental health support group and supports for sustainable travel to campus. 
The module was first introduced in Spring 2020 with 38 participants. This has risen to the maximum of 50 registered students in Spring 2021, with additional students on a waiting list. Due to the success of the module, the number of students will be increased for 2022 .

\section{Discussion}

Use of experiential learning by Healthy UCD has been very successful. By requiring students to plan and implement a real-life event, they gain valuable experience which they can later apply when they enter the working world. The events run by students enrich the university community, providing all students and staff with opportunities to learn more about wellbeing and come together to explore common interests. The growth in interest and participation levels in the modules that include experiential learning opportunities and the healthpromoting events that result from them show that this learning method is well received by students and that there is scope for experiential learning to be introduced in more modules.

Evaluation of the learning experience is vital for both students and the facilitating staff to enable the students to reflect on their own learning and for staff to provide improved guidance to subsequent students taking part in the modules. For example, it has been repeatedly observed that students can place more importance on development of the content for events than on promotion and spend the majority of their time and energy on the former whilst potentially neglecting the latter. While the content of an event is vital to attract people's interest and deliver an interesting event, this approach has sometimes led to certain events not attracting the level of participation or attendance that they deserve. After observing this, Healthy UCD staff have placed more emphasis on promotion and communication during planning meetings in an attempt to ensure that the students' dedication is rewarded with high participation levels in their events. Additionally, feedback from students themselves, such as the view that more preparation time is needed for Healthy Eating Week, will be taken on board in the future to further improve the learning experience.

Universities play a key role in society. They have an opportunity to influence students at a critical juncture in their lives - the transition to adulthood. Therefore, this is the ideal time to encourage them to create healthy habits and foster an interest in health promotion which will stand to them throughout their future lives and careers. This societal role of the university is recognised through the Times' Higher Education Impact Rankings which assesses and ranks universities according to how they work towards implementing the United Nations' Sustainable Development Goals (SDGs). UCD is currently ranked $22^{\text {nd }}$ out of 1,115 higher education institutions assessed. Of particular note are its high positions for SDG 11: Sustainable Cities and Communities, where UCD is ranked $16^{\text {th }}$, and SDG 3: Good Health and Wellbeing, where UCD is ranked $62^{\text {nd }}$, having increased its ranking in this category by 18 places since 2020 ("Impact Rankings 2021," 2021). The activities of Healthy UCD 
contribute towards these excellent rankings, including its implementation of experiential learning in health and wellbeing courses. The UCD strategy for 2020-2024, "Rising to the Future", also acknowledges both the role of Healthy UCD and the SDGs in its key themes of Creating a Sustainable Global Society and Building a Healthy World ("UCD Strategy 20202024," 2021). UCD is ranked in the 250-300 band in the Times Higher Education World University rankings ("World University Rankings," 2021). Recent research has shown that the more positive actions a university disclosed relating to its SDG achievements, the better its position in the overall ranking was likely to be (De la Posa, Merello et al., 2021). The provision of experiential learning and engagement in health \& wellbeing therefore provides gains both for students and for universities, through promotion of sustainability and good health and simultaneous advancement of international standing and reputation.

Several challenges have arisen for both staff and students involved in Healthy UCD's experiential learning initiatives, the most notable being the sudden shift to online learning necessitated by the Covid-19 pandemic. Students and staff were required to adapt at short notice to deliver the learning experiences and events remotely in a fully virtual setting. This has provided students with a different learning experience where they cannot rely on traditional methods of communication and engagement with the university community through in-person events but encourages creativity in how their plans are promoted and implemented.

To conclude, experiential learning has been successfully implemented in three key health and wellbeing related modules in UCD. The experience gained through participation in these modules has been favourably viewed by students, while Healthy UCD has successfully increased awareness of its work through module involvement, thereby furthering its aim to create a sustainable healthy campus for all in UCD. Regular evaluation and feedback from students are key to further develop experiential learning in these modules and potentially others to ensure an optimal learning experience for students where they feel fully supported. University campuses provide an ideal location for experiential learning which should be exploited for the benefit of students and society.

\section{References}

De la Poza, E., Merello, P., Barberá, A., \& Celani, A. (2021). Universities’ Reporting on SDGs: Using THE Impact Rankings to Model and Measure Their Contribution to Sustainability. Sustainability, 13(4), 2038. doi:10.3390/su13042038

Event Management, Autumn Trimester (SMGT20010). (2021). Retrieved February 18, 2021 from

https://sisweb.ucd.ie/usis/!W_HU_MENU.P_PUBLISH?p_tag=MODULE\&MODULE $=$ SMGT20010 
Event Management, Spring Trimester (SMGT20210). (2021). Retrieved February 18, 2021 from https://sisweb.ucd.ie/usis/!W_HU_MENU.P_PUBLISH?p_tag=MODULE\&MODULE $=$ SMGT20210\&TERMCODE $=20 \overline{2} 000$

Franco Valdez, A. D., \& Valdez Cervantes, A. (2018). Retailing Laboratory: Delivering Skills Through Experiential Learning. Journal of Marketing Education, 40(1), 17-30. doi:10.1177_0273475317753679

Healthy UCD. (2021). Retrieved February 18, 2021 from https://www.ucd.ie/healthyucd/

Healthy UCD | Healthy Eating Week 2019. (2021). Retrieved February 18, 2021 from https://www.ucd.ie/healthyucd/newsandevents/events/healthyeatingweek2019/

Healthy UCD | Healthy Eating Week February 2020. (2021). Retrieved February 18, 2021 from https:/www.ucd.ie/healthyucd/newsandevents/events/healthyeatingweek2020/

Healthy UCD | Healthy Eating Week November 2020. (2021). Retrieved February 18, 2021 from https://www.ucd.ie/healthyucd/discover/healthyeatingweek2020/

Healthy UCD | Healthy UCD Strategy. (2016). Retrieved February 18, 2021 from https://www.ucd.ie/healthyucd/about/healthyucdstrategy/

Impact Rankings 2021. (2021). Retrieved May 7, 2021 from https://www.timeshighereducation.com/impactrankings

Kolb, D. (1984). Experiential Learning: Experience As The Source Of Learning And Development: Prentice-Hall.

Practice Placement (non-acute) (PHPS40910). (2021). Retrieved February 18, 2021 from https://sisweb.ucd.ie/usis/!W_HU_MENU.P_PUBLISH?p_tag=MODULE\&MODULE $=$ PHPS40910

Seow, P.-S., Pan, G., \& Koh, G. (2019). Examining an experiential learning approach to prepare students for the volatile, uncertain, complex and ambiguous (VUCA) work environment. The International Journal of Management Education, 17(1), 62-76. doi:10.1016/j.ijme.2018.12.001

Student Health \& Wellbeing (PHPS10010). (2021). Retrieved February 18, 2021 from https://sisweb.ucd.ie/usis/!W_HU_MENU.P_PUBLISH?p_tag=MODULE\&MODULE $=$ PHPS 10010

UCD Strategy 2020-2024. (2021). Retrieved May 7, 2021 from https://strategy.ucd.ie/\#editor_2

University College Dublin - UCD by Numbers. (2021). Retrieved February 18, 2021 from https://www.ucd.ie/about-ucd/about/ucdbynumbers/

World University Rankings. (2021). Retrieved May 7, 2021 from https://www.timeshighereducation.com/world-university-rankings/2021/world-ranking 